\title{
46
}

\section{Reflections of a computer scientist for teachers and teacher educators}

\author{
Susan M. Merritt \\ Pace University \\ New York \\ USA
}

\begin{abstract}
This reflective essay describes three 'revolutions' which are underway and which will profoundly affect education. The first two are widely accepted: the computer revolution and the more recent telecommunications revolution. The third revolution is not well understood or appreciated by teachers and teacher educators; it is the revolution, or perhaps more appropriately, the evolution of the new discipline of computer science. The paper describes briefly one computer science curriculum which has been developed for high school students, and argues that more integration of computer science into teacher preparation and K-12 (secondary) education is essential for the future.
\end{abstract}

Main conference themes: informatics as study topic

Educational areas: secondary education, higher education

Study topics: computer science/informatics

Secondary keywords: 


\section{INTRODUCTORY REMARKS}

While I am not a K-12 (secondary education) teacher nor, technically, a teacher educator, I feel kinship with teachers. Before I returned to graduate school for a Ph.D. in computer science I spent some years in the early 1970s teaching secondary school mathematics. During the early years of my college teaching I taught many teachers. Those were the days in which an institution taught one or two computer classes a year to all who were interested. Many students were mathematics and science secondary school teachers who were eager to learn everything they could about computing. Today programs in the School of Computer Science and Information Systems of Pace University support both masters and baccalaureate degree programs in the School of Education.

Three major revolutions are underway which are important to education: a computer revolution, a telecommunications revolution and a computer science revolution. I note that teachers and teacher educators have (or soon will have) embraced the first two, but have remained relatively ignorant of the third, and propose that this state of affairs is not good for education.

\section{A COMPUTER REVOLUTION}

The so-called 'computer revolution' began some forty-eight years ago. One of the first electronic digital computers was the ENIAC developed in 1946. It is said to have weighed some 3 tons, had in it 30,000 vacuum tubes, failed every seven minutes, needed to be housed in a building as big as an airplane hangar and cost several million dollars.

Today you can buy a computer which is tens of thousands of times more powerful than the ENIAC, thousands of times cheaper, the weight of which can be measured in ounces and which might not fail for years. If what has happened in the computer industry had happened in the automotive industry, we could now buy a Rolls Royce for $\$ 2.75$ and it would go three million miles to the gallon [1].

The microcomputer or personal computer revolution began in the late 1970s with the development of the silicon chip and the development of the spreadsheet VisiCalc, in 1978. This development ties in with the 'intermediate technology' or 'alternative technology' school of thought that is: small, simple, cheap and respectful of natural resources. It is the kind of technology put forward by the British economist E. F. Schumacher in his book Small Is Beautiful [2] and other books. For the western world, computers are truly an intermediate technology. These are small, cheap, simple, use modest resources and are as such accessible and usable by human beings, and empowering. 
Now the possibilities are unlimited. As predicted recently at the ninth international conference on technology and education (Paris) by the keynote speaker, Professor Jacques Hebenstreit:

"In less than five years we shall be able to buy a pocket computer; with a colour liquid crystal display (LCD) screen with $10 \mathrm{MBs}$ of random access storage (RAM) and $100 \mathrm{MBs}$ of disk storage for under $\$ 500$. It will be possible for each student to have a computer available at all times ... Multimedia computers will be widely used with publishers producing teacher and learner support materials for those computers. This coupled with local and global information networks, has the potential to reshape the way education is conceived and delivered."

\section{A TELECOMMUNICATIONS REVOLUTION}

The second revolution going on right now is a communications revolution. In his remarks above, Hebenstreit links very simple pocket computers with networks. That is a very, very powerful combination. Let me cite some very simple examples.

I have a laptop computer. The University is on Internet and I personally hold a subscription to a commercial telecommunications service which costs less than $\$ 100$ a year. On a trip to the western United States this summer some numbers related to a budget were needed by a colleague; in my hotel room I pulled out the laptop, ran the numbers, plugged into the phone in the room, signed on and sent the page of numbers to a fax machine in the office in New York City where it printed out seconds later. I could also have sent it to myself to the fax machine in the hotel, I could have indicated that it be sent by U.S. mail or I could have e-mailed it (that is, used electronic mail) to someone else on virtually any network in the world.

A few years ago Arno Penzias, the Nobel prize winner, has said that something like five years ago there were perhaps 100 times as many keyboards as fax machines, but now there are 10 times as many, and in five years there will be 100 times as many fax machines as keyboards-in offices, homes, and cars. (He pointed out that while it is hard to type while driving, it is not so hard to fax). We now see executive centres with PCs, fax machines and copy machines in health clubs, hospitals and restaurants.

You have no doubt been reading about the Internet, and you may be confused. But some of the power is very simple to understand: if you have a problem you can send it out to 10,000 people and get, say, 250 possible solutions. For a few years now I have accessed a network called systers, 
which is made up of women in computer science, currently about 2,500 around the world. It is free, as are many, many special interest networks and accessible from the Internet. The 'discussion' has to do with issues related to women and computer science, and all sorts of things arise; for example, a message might be sent: I am looking for ideas about how to interest my 12 year old daughter in science and mathematics, and many responses will come back, including recommendations on books to read, summer workshops to go to, and so forth and so on.

The telecommunications revolution boggles the mind, it is: 'The Network In Your Computer'. The point is that although we have come to think about having a computer and even connecting it to a network, what we really have before us is a network - any numbers of networks - 'in' our computers, virtually in the same way as we have memory and hard disk space 'in' our computers.

I am not trying to engage you with 'gee whiz' hype, but as a technologist who is very, very interested in the human side of things, I find networking incredibly exciting. Also it is small, simple, cheap and does not abuse natural resources. It can be a tool for the advancement of people. It opens up the possibility of one to one, one to many, many to one and many to many communication which has not existed before, even with the telephone or the radio.

Another my interests is technology and the developing world. Networking may sound as if it depends upon an existing telephone infrastructure, but now there are radio modems for connecting to a radio network rather than a telephone network. This makes computer networks accessible virtually everywhere in the world including remote rural areas of the developed world and throughout the less developed world.

This is the telecommunications revolution which in the United States dates back to the early 1980s and was stimulated by the divestiture of AT\&T. The revolution is only a decade old.

\section{A COMPUTER SCIENCE REVOLUTION}

There is a third revolution which is most intimately related to what I do. It is the volatile mix of engineering, mathematics, psychology, cybernetics, philosophy and organizational theory from which emerged the discipline of computer science, or informatics. While the computer was invented some 48 years ago, the discipline, the organization of the body of knowledge, is only upwards of two and a half decades old dating back to the establishment of the first Ph.D program in computer science. I recall giving a short talk to the University Board of Trustees to describe what shape education in our colleges would take 
over the next decade, that is, beyond the year 2000 . When I had my turn, I noted that all of the other disciplines were at least twice as old, some many times as old as mine and that in my discipline Herbert Simon, the Nobel laureate and many others-Bell, Toffler, Naisbitt, Fegenbaum, McCorduck, Forester and Zuboff-have taken on similar tasks with misgivings.

Nevertheless, there is a body of knowledge which is computer science. Because of the rapid dynamism of the technology that body of knowledge is absolutely critical to know because it holds true for the various generations of the technology. Programming, for example, the basic skill of a computer scientist which is what writing is to a novelist and what mathematics is to a physicist, is arguably the same now as it was in 1946 even though the forms and symbols have changed. The discipline, the way of thinking has developed, but not changed. The conceptual idea behind a computer has remained the same since 1946; there are major leaps in variations and nuances, but the idea is the same as that which was conceived (in fact) before the first computer was built. The central notion of an algorithm is absolutely key to computer science and it is timeless. Data structures are very basic concepts, fundamental to computer science and understandable even by children. (My niece in the first grade had a section in her science book called 'Separating and Storing.' Shells, rocks, leaves and other items were gathered into different compartments of a rectangular box.)

I claim that computer science has infiltrated our culture and cultural understanding. We use words like input and output as both nouns and verbs, we talk about parallel processing when we do many things at once, and we talk about RAM, megabytes and megahertz. The discipline of computer science has permeated our culture in much the same way as, for example, nuclear physics (atoms and molecules) has or as genetics (DNA, chromosomes and genes) has. Atoms and molecules, genes and chromosomes are now part of $\mathrm{K}-12$ secondary curriculum. Similarly, I maintain that computer science (not just computer technology) needs to be part of K-12 education.

\section{A NEW DISCIPLINE}

For the last four years I have been the chair of a committee of the Education Board of the Association for Computing Machinery (ACM), a scientific and educational society. This committee has developed a year long college preparatory computer science course for all high school students. (The report is published in full by the ACM [3], and in part in various educational journals [4].) The idea of the course is that it is like biology, chemistry, physics, or math, both in its rigor and in its status in the curriculum. We note that in the United States computing is typically relegated to a half year scheduled 
against things like driver education. We note that computing courses are not considered major sciences which are expected for students applying to college. We note that sometimes a computing course is perceived as being for the student who wants to go on in computer science, unlike biology or chemistry which is expected of everyone. There is really no high school computer science course in the United States tested on entrance examinations.

The third revolution has been the evolution of a new discipline. It has been my experience that the discipline is perceived to be for specialists, if it is acknowledged at all, and I would maintain that this is a very narrow view. While the computer revolution and the telecommunications revolution are mind boggling, they sit on the foundation of what is a new and exciting body of knowledge which, by its manifestation through its applications, is changing the way we think, perhaps the way we feel and certainly the way we perceive the world. Like atoms and molecules, some of that body of knowledge needs to make its way into the school curriculum.

\section{EDUCATORS' RESPONSE}

The computer revolution has been accepted by educators and students. What Professor Hebenstreit said has begun to happen: very soon a very powerful, small machine will be available for very little cost. Publishers will supplement everything with software and the schools will be inundated with computers. So educators will need to be able to use applications on computers and be able to teach in an environment in which small personal computers abound. Most educators realize the significance of this revolution and have either become computer literate, or believe that they should.

The telecommunications revolution is about to profoundly change our lives, and it is just beginning. It will necessarily affect our schools and perhaps our homes. In terms of computer applications in education telecommunications is the most significant development in educational computing, possibly the only significant development beyond the standard productivity tools which are word processing, spreadsheets and databases [5]. Telecommunications applications allow students to collaborate with students across the globe, to do research together, to create literature and other art together; these allow teachers new creativity and collaboration with other teachers, and they enhance the possibility of student centred classrooms. Many educators realize the coming impact of telecommunications and are delayed in getting started only in awaiting a modem or a telephone line.

However, the third revolution remains a silent one. While both the computer and the telecommunications revolutions are happening within a culture resting 
upon the foundation of computer science, most educators and students remain ignorant of the discipline.

So my response is simple: $\mathrm{K}-12$ secondary teachers and students must learn the fundamentals of computer science and apply these as broadly as possible. That, by the way, is somewhat radical. Many computer scientists would say: teach the fundamentals and apply them narrowly, that is to a computer, or an operating system, or a programming language; I would say: apply these to develop a simulation for the dissection of a frog.

Computer science has recently suffered from its chauvinistic ignorance of application areas, particularly in education, and recent reports support that view. I personally value partnerships such as the one with the School of Education and believe that such partnerships are vital. In many ways the computer science/education partnership is basic. For example, the field of cognitive science is a marriage between knowledge about learning and computer science. And education is the 'ultimate information system'. So as we study about information systems surely we need to study about education, and vice versa.

I would advise teachers and teacher educators to also learn the fundamentals and apply them broadly, and not necessarily in that order. I believe that we sometimes make a mistake in computing by teaching the fundamentals first; we should start with some of the exciting applications. But also much is to be gained by understanding the underlying fundamentals-a word processing or desktop publishing program, for example, using very interesting algorithms and data structures. The advice to learn the fundamentals and apply these broadly of course implies a learning environment which is characterized by computers and communications. In such an environment the learning of computer science fundamentals is a natural and necessary activity.

What is meant by fundamentals? Future teachers need to know the basic productivity tools including word processing, spreadsheets, data bases, hypermedia and telecommunications. And they should survey the application software in their area. And perhaps the most important: they should apply these things in real, hands-on, visceral ways. They should actually build learning applications themselves with hypermedia and telecommunications which in computer science jargon is called a software engineering project. To do that freely and well they need to know some computer science: problem solving, programming, algorithms, the abstract machine and object oriented ideas. This similarly applies to students. This can be done with curricula like the ACM High School Computer Science Curriculum. Similar curricula need to be developed for introducing the ideas into elementary education.

A newspaper piece recently claimed: "In poor schools children are taught to type, not to think." In some sense this underscores my point. Computers which can do word processing can do anything. How can the enormous power 
of computing, and perhaps even more so of telecommunications which has the potential of making the very best teaching and learning experiences accessible to all students, be brought to bear on thinking and learning? And how can teachers be instruments and advocates of that? And how can we teach them to be? And I say: the key is in computer science.

\section{CONCLUDING REMARK}

Will technology completely change the notion of schools as we know them? To go back to Professor Hebenstreit's question: Will technology change the way education is conceived and delivered?

I think it can. Back in the 1960's when I was in college I enjoyed Ivan Illich's DeSchooling Society [6]. In the face of computer networking his proposal of learning networks - peer to peer, apprentice to master, student to resources, and so forth-is a very interesting one; and Illich was not talking about electronic networks, but about human ones. The amazing thing is that his model can now be implemented electronically in an environment in which small, simple, cheap, and very powerful computers, are networked in previously unimaginable ways. It could replace schools as we know them.

\section{REFERENCES}

1. Evans, C. (1979) The Micro Millennium. Washington Square Press, New York, NY.

2. Schumacher, E.F. (1973) Small Is Beautiful. Harper \& Row, New York, NY.

3. Association for Computing Machinery. (1993) ACM Model High School Computer Science Curriculum, ACM, New York.

4. Merritt, S.M. et al. (1993) ACM Model High School Computer Science Curriculum. Communications of the ACM 36 (5); The Computing Teacher and J. of Computer Science Education 8 (1).

5. Merritt, S.M. (1991) Telecommunications Software: The Community Networking Model. International J. of Computers and Education 17 (4).

6. Illich, I. (1971) DeSchooling Society. Harper \& Row, NY. 